\title{
PRESSURE SORES: CAUSATION AND COST, BIOMECHANIGS AND PREVENTION
}

\author{
M. T. MANLEY, Ph.D. (Bioeng.), B.Sc.*
}

\section{INTRODUCTION: PRESSURE SORES}

The load bearing skeletal system and the vital organs of the body are isolated and protected from the external environment by a continuous layer of skin and subcutaneous tissue. In consequence when we stand, sit or lie, the areas of skin which are in contact with the supporting surface are subjected to both normal and tangential force components of the body weight. Those forces compress and deform the layers of soft tissue through which they act, and such deformation may interfere with the cutaneous capillary blood supply, which, if maintained, leads to tissue death and the formation of a pressure sore.

It is thus apparent that man is not designed to remain immobile for long periods of time. His natural reaction to imposed immobility is to randomly make small adjustments in posture or position whether he is awake or asleep, the "fidgeting" being partly stimulated by the feeling of discomfort caused by localised tissue ischaemia. Unfortunately the chronically ill, the aged, and the immobilised have lost this protective mechanism, and these patients are most liable to suffer from pressure sores.

Traditionally, the prevention of pressure sores has been considered as a nursing problem and the presence of sores as a manifestation of inadequate nursing care. However, the increasing numbers of immobilised and handicapped patients worldwide have focused more attention on the problem and it is now accepted that some of the factors in pressure sore aetiology are inadequately understood.

Basic research is being carried out worldwide into the effects on soft tissue physiology of mechanical stress, inadequate nutrition, chemical irritants, and moisture. In addition, devices to prevent sores developing in the chronic patient are being developed.

This paper describes the biomechanics of pressure sores in the sitting and bed-bound patient and discusses some of the techniques which are now available for sore prevention.

\section{INCIDENCE}

The incidence of pressure sores in the patient community has only been investigated relatively recently and information is still somewhat scant. Data currently available includes the results of definitive surveys conducted in a large hospital population in Cape Town (Manley 1978), in the total patient community in Glasgow (Barbenel $e f$ al. 1977) and in the total population of the county of Aarhus in Denmark (Petersen and Bittman 1971). It was shown by all three surveys that the overall incidence of patients with pressure sores is about $9 \%$ of the total patient population, although the incidence increases significantly with increase in patient age. In Cape Town, for example, about $20 \%$ of the patients surveyed were over retiring age and this $20 \%$ had about $50 \%$ of the pressure sores found. The Glasgow survey produced the most dramatic age related data, as in the total patient community of that city (hospital patients plus home based patients) $65 \%$ of the patients surveyed were over retiring age, and these patients

\footnotetext{
* Senior Lecturer, Department of Biomedical Engineering, University of Cape Town.
}

contributed $83 \%$ of the pressure sores recorded. Other factors found to predispose to pressure sores were incontinence, immobility and unconsciousness. However, all results showed that the strongest single predictive factor was age. An interesting result which emerger from the Cape Town survey was the disparity in pressure sore incidence among different racial groups. It was shown that in the general hospital population the ratio of caucasian to negroid patients with sores was about $20: 1$, a result which still requires a satisfactory explanation.

\section{THE BIOMECHANICS OF PRESSURE SORES}

\section{Soft Tissue Mechanics}

In mechanical terms, human tissue is a visco-elastic material; that is, it has an elastic component and also a viscous or flow component. Thus, when a load is applied to an area of skin, the material undergoes an immediate initial deformation through its elastic component and with time the viscous component allows the initial deformation to increase without increase in the applied load. This phenomenon is known as creep, and deformation of tissues is said to be time-dependent.

The effects of forces upon human soft tissues and skin have been extensively studied in the laboratory (Fung 1972, Kenedi et al. 1975, Gibson et al. 1976). The simplest test is to apply a tensile force of known magnitude to a parallel sided specimen of skin and measure the longitudinal elongation and simultaneous lateral contraction of the specimen. If the force is increased in incremental steps the type of curves shown in Fig. I can be plotted. Curve A is longitudinal percentage elongation ("strain") plotted against applied force. The curve shows that a skin specimen undergoes a large initial deformation on the application of a small force. As applied force increases each incremental step produces progressively smaller increases in specimen deformation. Eventually a relatively linear region is reached where extension or lateral contraction increases linearly witlapplied force. Complete removal of the force from th tissue specimen allows the specimen to return to its original length, although the recovery process does not occur instantaneously, and the original length may not be regained for some hours.

Once the specimen has returned to its original resting dimensions the experimental procedure can again be repeated. However, the force/strain curve now obtained is shown by curve $B$ in Fig. 1. This curve shows that

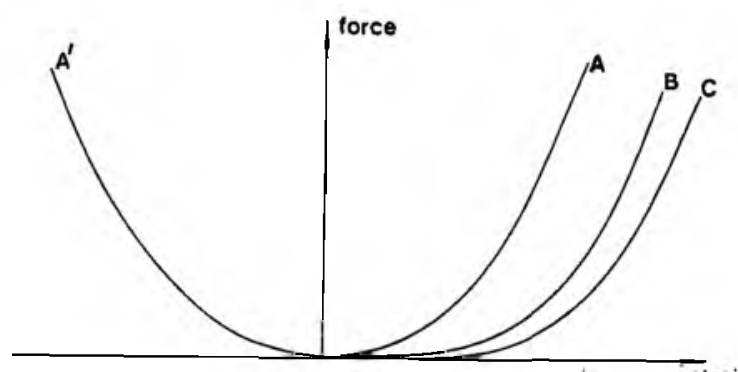

strain 
the first loading cycle has apparently given the specimen the compliance, and an increased deformation can greate observed at each step in the second loading now bure. Unloading and then reloading on a third procedur will again produce an apparent change in occasical characteristics (curve $C$ ) but thereafter the mechan exhibits stable characteristics and is said to be tisste exditioned (Daly 1966, Finlay 1970, Starke 1971). pre-condition studies like these have clearly shown that Le magnitude of soft tissue deformation depends not the magnitude of the applied load, but also unon time of application and the repetitive nature of upo loading cycle. Such results have obvious clinical implications.

Finally, an understanding of pressure ischaemia demands that the loading profiles applied to soft tissue maning sitting, lying, or walking must also be studied. When we lie, sit, or stand our body weight is not evenly distributed across the area of skin in contact with the support surface. The body is not a rigid structure, and therefore the force applied at the body/ support interface in one area will differ from the brce applied at the interface at an adjoining area. In engineering terms the critical measure is not simply the magnitude of applied force but the ratio of this force to the surface area over which it acts. This ratio is known as the stress and is a measurement of force intensity. In the clinical world, stress is usually loosely referred to as "pressure" and reference is made to the pressure between a subject and support surface. "Interface pressure" is usually measured and specified in millimetres of mercury $(\mathrm{mmHg})$ and this common usage will be adhered to in this article. It is generally accepted that sores can be prevented if the interface pressure at a bony prominence is less than mean capillary blood pressure ( 30 to $40 \mathrm{mmHg}$ ), as under this condition capillary blood flow is maintained and not arrested by the applied load.

\section{PREVENTION OF SORES}

\section{THE RECUMBENT PATIENT}

The projected area of support of a supine patient when divided by his body weight yields an average pressure of around $20 \mathrm{mmHg}$, which is well below mean capillary blood pressure $(30$ to $40 \mathrm{mmHg}$ ). Thus, if a patient is evenly supported over the complete posterior of the body, pressure sores will not occur. The simplest jethod of achieving a whole body support situation is $b$ "float" the body in a suitable fluid, and some successful prevention devices use this flotation principle. Other approaches use shaped elastic foam to remove loads from bony prominences, or high compliance elastic foam to equalise support pressures. Mechanical devices which compensate for the patient's inherent lack of mobility and spontaneous movement by shifting the body weight at regular intervals can also be used with success.

\section{Liquid Support (Flotation) Beds}

Probably the simplest form of liquid support system is the "water flotation bed" which consists of a tub filled with warm water, the surface of which is covered with an extremely loose fitting sheet of synthetic rubber or vinyl. Because of the looseness of the sheet the patient literally floats in the water and is supported by hydrostatic pressure alone. However, if the water surface is covered by a tight sheet or membrane, the patient is supported by a combination of hydrostatic pressure and membrane tension. Membrane tension support is known as "hammocking", and is a potential problem in all types of fluid support systems, as the soft tissues are then subjected to both shear forces and increased

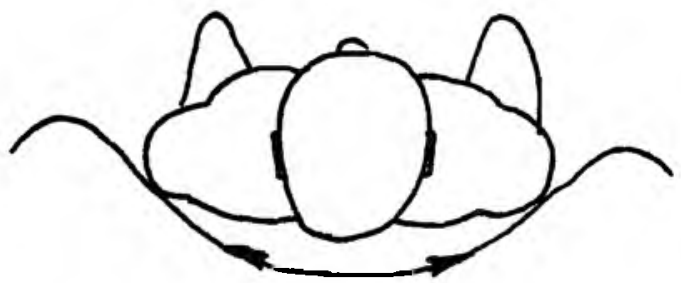

'Hammocking'

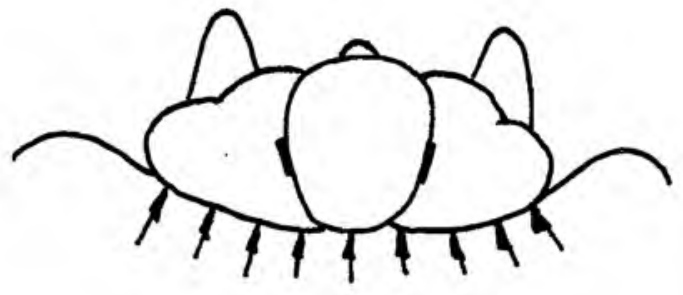

Fluid Support

Fig. 2

interface pressures. Correct hydrostatic support and the incorrect membrane tension support are shown schematically in Fig. 2.

An inherent disadvantage of the water flotation system is the unnatural posture adopted by the patient; floating in a three-quarter submerged position with hips and knees flexed and face just above the surface. In addition, the body is only marginally stable in the water and nursing operations are difficult on the unstable platform offered by the water surface.

A development of the water bed first described by Reswick (1972) is known as the "Rancho flotation bed" or "mud bed" in which the containing tub is filled with oilwell drilling mud. Again the surface of the supporting fluid is covered with an extremely loose fitting vinyl sheet and the patient is supported by hydrostatic pressure. Oilwell drilling mud has a density approximately twice that of water and therefore the body only sinks half as far into the supporting medium. The greater density and viscosity of mud compared to water ensures that stability is markedly improved and that the patient floats in a more comfortable position. Fig. 3 compare the "floating" position of patients in both water and mud beds.

One of the practical problems which arises in the use of liquid support beds is the weight of the bed once it has been filled with the supporting fluid. For example. a mud bed which contains about 250 litres of mud weighs in excess of $500 \mathrm{~kg}$. In addition, the temperature of the supporting liquid must be carefully controlled to ensure that the patient is not heated or cooled.

\section{Air Support Systems}

Two major types of air support systems, known as high air loss and low air loss beds, have been developed. The high air loss bed was developed primarily for the treatment of major bum injuries and the patient is supported by a high volume flow of temperature controlled air at low pressure. The air is passed into the base of a coffin shaped box which contains the patient, 


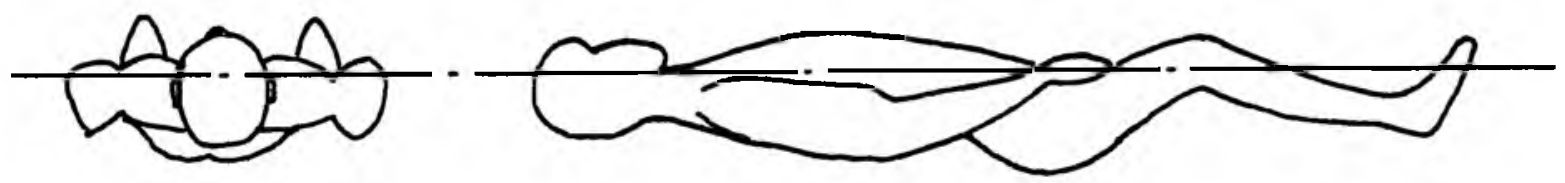

WATER BED

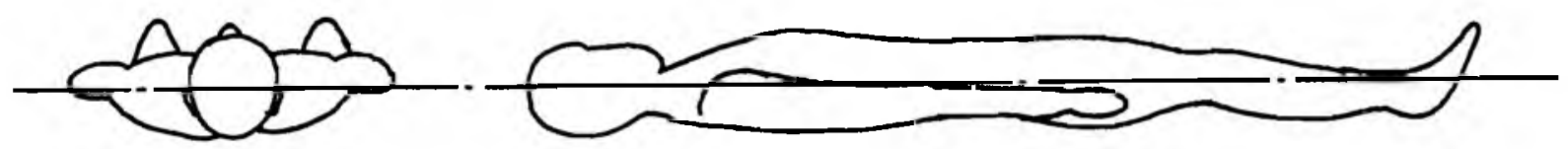

MUD BED

Fig. 3

and as the air exits to the atmosphere, the patient's body is lifted clear of all supporting surfaces and "hovers" in the box. The system has some application in pressure sore prevention but is unpopular with patients, noisy and difficult to manage.

The low air loss bed (Scales 1976) was designed specifically for prevention of pressure necrosis. The bed is constructed of 21 air sacs fabricated from a microporous polyurethane coated nylon fabric which is permeable to water vapour but which is impermeable to air. Moisture collecting between the patient's body surface and the sac permeates the membrane into the air space, the volume flow of air through each sac and the moisture removal from the patient's skin surface being controlled by a system of outlet valves. Body weight is supported by the 21 sacs, the pressure in each sac being adjusted to suit a particular area of the patient's anatomy. Typical pressures are: head, trunk, and seat group of sacs $-20 \mathrm{mmHg}$; thigh $-10 \mathrm{mmHg}$; calf and foot $-6 \mathrm{mmHg}$.

Finally a quasi-fluid bed "the Fluidised Sand Bed", requires brief consideration (Stewart 1976). The bed consists of a box or tray full of fine sand, the base of. the tray being constructed of a steel micropore mesh. In operation a patient is placed on a sand surface and air is passed from a blower into the base of the tray to generate a "quicksand" effect. The patient sinks slowly into the sand and when a suitable body contour has been formed the supplied air is switched off, and the patient is supported by a surface which is in intimate contact with the body. The interface pressures obtained by this method have not been published, but the sand bed is said to be very successful in preventing sores.

\section{Dynamic Support Surfaces}

The fluid support beds described above attempt to achieve an acceptable static redistribution of pressure and thus allow the patient to lie in one position for long periods of time. Dynamic support surfaces relieve pressure ischaemia by constant adjustments in the posture of the patient, and thus attempts to replace the normal physiological "fidgeting" response to imposed immobility. In their simplest form they are a standard bed and mattress fitted onto a "rocker" arrangement, but such turning beds are unpopular and of little benefit. The more acceptable type of dynamic support surface is the so-called "ripple mattress", variations of which can now be obtanied from several manufacturers. The ripple mattress consists of a multicellular or multitube air mattress, about $75 \mathrm{~mm}$ thick, the tubes being progressively inflated and deflated with air to produce a ripple effect. Ripple mattresses are relatively inexpensive, simple to use, and often extremely effective in preventing sores.

\section{THE SITTING PATIENT}

It has been shown that the highest interface pressures encountered while sitting occur between the support surface and the ischial tuberosities, and peak pressures in the order of $300 \mathrm{mgHg}$ have been measured in this area from subjects sitting on a wooden chair (Manley et al. 1977). Even when a patient is sitting on a soft foam cushion, capillary occlusion may still occur as the interface pressures beneath the tuberosities is often in excess of $100 \mathrm{mmHg}$. Additionally, if there is a tendencr for the buttocks to slip forward in the chair, frictiont. or shear forces will further deform the loaded tissues and cause further occlusion of capillaries.

Numerous methods have been proposed for preventing sores in sitting patients and many different types of seat cushions or pads are now available. Cushions designed for long-term sitting can be subdivided into passive or active categories, the passive cushion attempting to redistribute statically the "natural" interface pressures while the active cushion provides a constantly changing patient/support contact area and thus cyclic tissue loading. Cushions which fall into the passive category including flotation pads which may be filled with air, water, or silicone fluid; bean bags consisting of cloth envelopes filled with dry macrospheres (usually polystyrene beads); gel pads of silicone or vinyl ge] enclosed in an impervious envelope or in closed cell foam; elastic foam cushions of latex or polyurethane: visco-elastic foam cushions which attempt to provide greater stability than the purely elastic variety; and custom-made vacuum formed seats which attempt to provide the maximum patient support contact area. Active cushions are usually of the ripple seat or alternating pressure pad variety, in which air or a support fluid is pumped through linked chambers or pipes to 
move bods weight ciclacalls from one allea w anosher Active device prevent the protonged applacallon of excessive interlace presture rather than reduce the magnitude of peat loads on the sillong alleat.

Both passise and actio success in presenting sores. Problems with support devices in the parise calcegen molude the invabilits. floppiness and werghr of flutd and gel pack, the heat retention propertace ol bean bags and the expense and

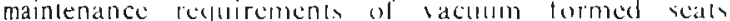
In the active calceors. rpple lspe vals are cumber-

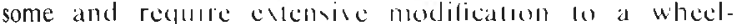
chair (including the addition of a pous vepplet a the can be expemse lo bus and matimlan thes alle not suitable for the magerits of wheclehase uners.

The simplest and leas ayensise silling uppon ver faces are construcled from elaste for bisco-clastic foant, and a large batis of pressure reliel cushion. construcled from foam materials atre commerciall a a ail able. Most of lhese cushions allempt to ploside a silling surface which conlorm lo lhe palient, bods bape. but funflicting derign requirements mean lhat high foan tensill and resilience are leyuired of perent botloming out" al the cushion. and a low foam demsits is required lo proside bolh a "soll lecl" and goosl com. cormabilits (onveyuchls, mans foam cushions are laminated from two or mose materials of different densition to proside a compromive solution: thos is not totally effeclise in perellting sures.

A foam cushion which has thown llsclt (o) be rer effective in both presonting and healing silling sores is

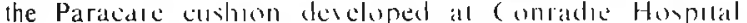

(Manles if al. 1977). I he cushion a construcled from expanded polvurethane elaste loam ol hegh densis which presents "bottoming out" of the petsis ante the wheelchair seal and a cuttoul under the ischii ensures that mose of the load which would hate been carried bs the luberositici is now carried on the "Irochanteric shell" and thighs (Fig. 4). In early designs of the Paracare cushion the cut-out was custom-fitled lo the anatoms of the indisidual pationt on envure that loading ivas completels remored from the tuberositas bul subseguents it has been shown that the inchit ean safels wilhsiand an incerlace premure ol about 40 motig. A bloch of low demils foam is now lilled mlo the cullout so that the tuberosition calrs a mall proportion of bods weight. and this weghl sharing between the trochanterice shelf and schii has atlowed the litling procedure to be simplilied so that onls lhree w/s of cushion cultoul now need be comslateled.

A complete Paracare cushion is shown in Fig. S. Ihe rasised front portion of the cushion structure enveres that the maximum posible load is transterred to the "sile" weightbearing area of the lhighs. while the curved base fills the sag in the whedchair hammoch seat and perents distorlion of the cul-oul dimenuson. on the upper surlace. The complete cushion in titled with a lwo-was slecteh labres which presents abrasse wear of the foam and reduces soiling of the cushion.

In addition to lhe paracare cushion, pattends at (onradic are also supplied with a shaped bachrest which is desiened to ensure a no-load condition on the acrum. coecs x, and wertebral procenses. The bachrest dhe enures that the palant, achil are pomlaned

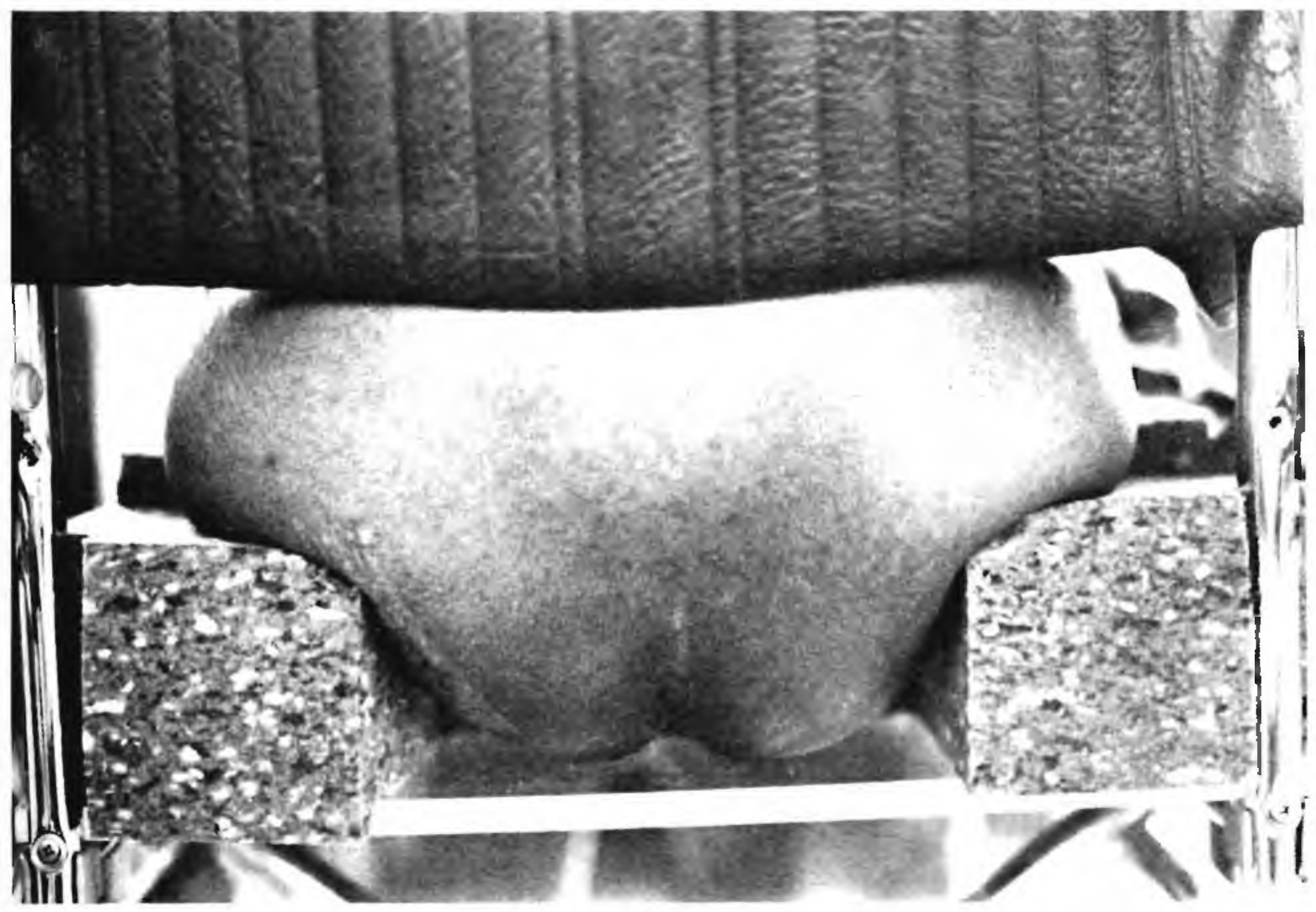

I is. +1 


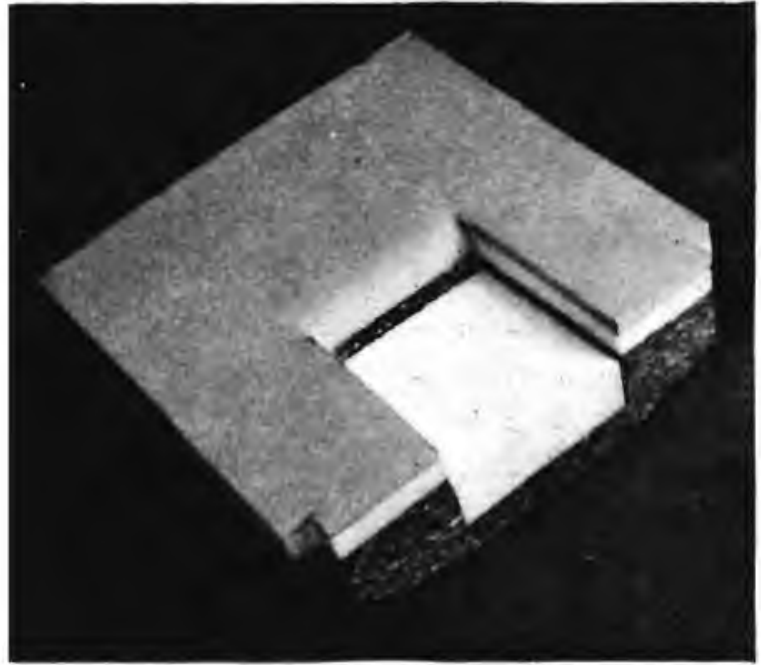

Fig. 5

correctl in the cushion cut-out, improves patient posture in the chair and provides lateral stability for patients with a high level of spinal lesion. Lumbar support is also provided for improved patient comfort and the backrest is again covered in two-wat stretch fabric. Location (1) the wheelchair is by elastic tapes over the wheelchair handles and bs "Velcro" lapes to the rear of the cushion cover. A complete Paracare seating sistem is shown in Fig. 6

\section{CONCLUSION: REHABILITATION ANID COST BENFIITS}

Ihe rapidl growing worldwide population of handicapped and helpless people has led to an escalation in health care costs. The Inited States. for example. now spends about 18 ". of its gross national producs on health care, and the atcrage cost to society for each patient treated has approximately trebled in the last eight rears (Kenedi 1977). There are now clear indications. particularls in the "caring" societics. that the financial and manpower demands of the health eare services mat ver soon outrun the resources that can bo allocated to them. In consequence, health care nusst become more cost effective. and patients must be rehabilitated and reintegrated into socich at the earliest possible slage in their treatment. It is evident that pressure sores. whether due to prolonged bedrest or to prolonged silting can onls dela! the rehabilitation process. and active steps taken at the earliest opportunity 10 prevent sores must increase the cost effectiveness of medical care.

\section{References}

I Barbencl. J. (.. Jordan. M. M and Nicol. S. (1977): "I he incidence of pressure sores". Lancet, 2. 548.

2. Dalı. (. H. (1966): "The biomechanical characterislics of human skin" Ph.D. Thesis. Univ. Strathclyde. Glasgow.

Finlas. J. B. (1970): "Biod namic sudjes of human skin" Ph.D. Thesis. Unil. Strathclide. Glasgow.

4. Fung. Y-C. (1972): "Stress-strain-histor relations ol solt lissuc in simple elongation" in Biomechanics its foundations and objectives. ed. Fung: publ. Prentice-Hall

5. (ibson. T. Barbenel. J. ( \& Fvans. J. H. (1970) "Biomechanical ( oncepers and E.fects" in Bedsore

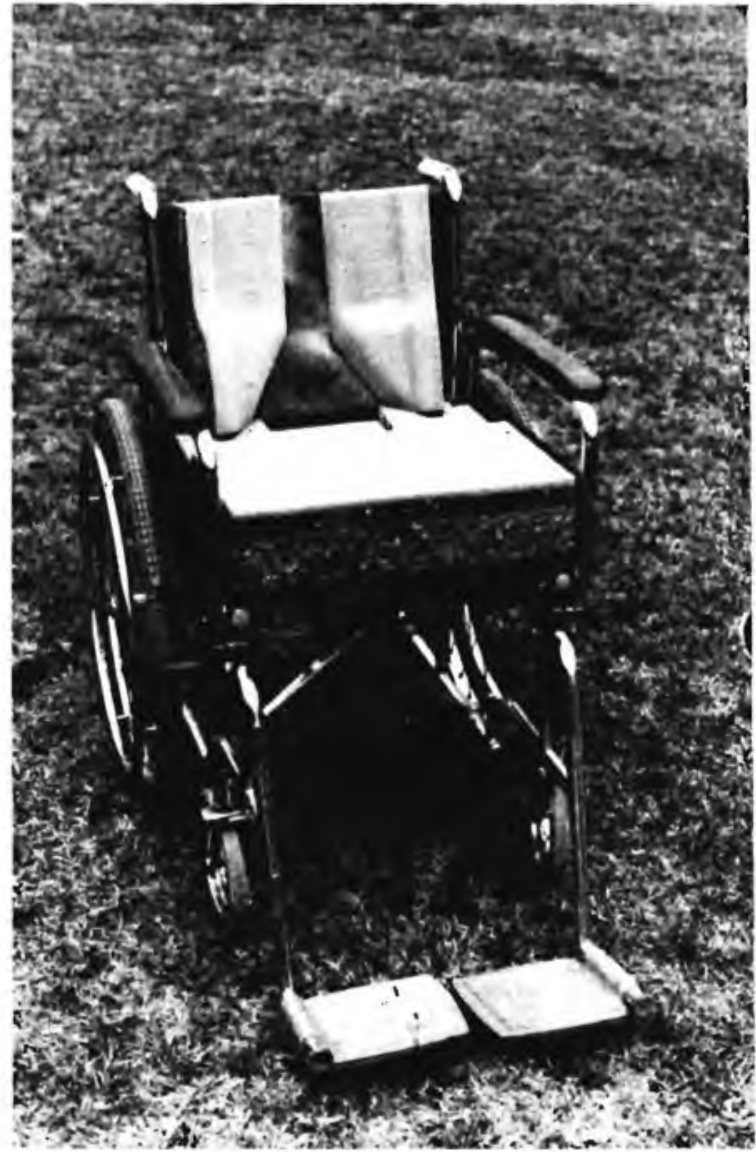

Fig. 6

Biomechanics. ed. R. M. Kenedi and J. Cowden: Macmillan Press.

6. Kenedi. R. M. (1977): "Engineering costs and Bcnefits in Health (are" in Proc. Internationa Conference in Bioengineering, (ape Town. Apr) 1977.

7. Kenedi, R. M., (iibson, I., Evans, J. H. and Barbenel. J. (". (1975): "Tisste mechanics". Plivs. Mid. Biol. 20. $699-717$.

8. Manles. M. T. (1978): "Pressure sores. contributor factors and costs" S. Afr. Mod. J., 53. $217-222$.

9. Manleı. M. T.. Wakelield. E. \& Kes. A. (i. (1977): "The prevention and treatment of pressure sores in the sitting paraplegic" I. Afr. Med J., 52. 771

10. Peterion. N. ( . and Bituman, S. (1971): "Epidemiology of pressure sores". Scand. J. Plast. Racousm. Sirrs. 5. 62.

11 Reswick. J, (1972): "Rancho Flotation Bed" in The Effect of Pressure on Soft Tissues. National Academs of Sciences. Washinglon.

12. Scales. J. T. (1976): “Air support sustems for the prevention of bed sores" in Bedsore Biomechanics. ed. R. M. Kenedi and J. Cowden: Macmillan Press

13. Stark. H. (1971): "The surgical limits of extension and compression of human skin". Ph.D. Thesis Univ. Strathclide. Glasgow.

14. Stewart. 1. M (1976): "Sand Bed Nursing" in Bedsore Biomechanics. ed. R. M. Kenedi and J cowden: Macmillan Press. 